\title{
RBEP
}

\section{Percepção dos estudantes universitários acerca do acesso à educação superior: um estudo exploratório}

Caterine Vila Fagundes

http://dx.doi.org/10.1590/S2176-6681/310212495

\section{Resumo}

Este artigo tem como objetivo descrever o perfil de acesso dos alunos de diferentes cursos de licenciatura da Universidade Federal do Rio Grande do Sul (UFRGS) e a percepção deles sobre a experiência educativa prévia ao ingresso à universidade. Discute-se, ainda, o desempenho acadêmico como indicador de qualidade do acesso à educação superior. Este estudo é do tipo exploratório-descritivo de abordagem quantitativa. Os dados foram obtidos por meio de questionário e procedeu-se ao tratamento estatístico recorrendo ao programa "SPSS" (versão 12.0). Evidencia-se, como resultado da amostra, um regular domínio de competências e habilidades adquiridas que facilitam o desenvolvimento de novas aprendizagens na educação superior. Conclui-se que é iminente a instauração de intervenções na orientação para o acesso à educação superior visando à qualidade do processo educativo.

Palavras-chave: acesso à educação superior; desempenho acadêmico; intervenção pedagógica. 


\section{Abstract \\ Perception of college students about access to higher education: an exploratory study}

This article aims to describe the access profile of students from different undergraduate courses at Universidade Federal do Rio Grande do Sul (UFRGS) and their perception about their educational experience prior to entering the university. The academic performance as an indicator of quality of access to higher education is also discussed. This study is exploratory, descriptive and quantitative. Data were collected by questionnaire and submitted to statistical treatment, using SPSS (version 12.0). Sample results indicate a regular domain of competencies and skills acquired that facilitate the development of new learning in higher education. It is concluded that an introduction of interventions on the orientation for the access to higher education, aiming at the quality of the educational process, is imminent.

Keywords: access to higher education; academic performance; pedagogical intervention.

\section{Introdução}

O prognóstico de que o século 21 promete poder e emprego aos que melhor desenvolverem suas faculdades intelectuais superiores (capacidade de análise, síntese, avaliação, flexibilidade e criatividade) serve de base a propostas que fundamentam a qualidade da educação na adoção de um único modelo curricular/educativo para todos os alunos. Essa premissa respalda-se, também, no estímulo ao modelo ou ao modismo de "educação por competências", termo definido pelo sociólogo e antropólogo Philippe Perrenoud (1999) como a capacidade de agir eficazmente numa determinada situação, apoiada em conhecimentos, mas sem se limitar a eles. A Lei de Diretrizes e Bases da Educação Nacional (Brasil, 1996) segue esse modelo, e configura a escola a partir de quatro pilares: aprender a conhecer, aprender a viver juntos, aprender a fazer e aprender a ser (Delors, 1999).

Com o apogeu do processo de globalização econômica neste inicio de século e, consequentemente, a permanente mudança no decurso do desenvolvimento social e pessoal, que resulta da expansão do capitalismo e das profundas modificações nas sociedades contemporâneas com a imposição de novos desafios, a tendência é trabalhar mais intelectualmente, com autonomia e capacidade criativa. Assim, as exigências desta sociedade não estão embasadas somente nos livros, na Internet e nas técnicas, mas fundamentalmente no indivíduo, que deve incorporar essas transformações aos seus valores. 
Tal contexto põe em cena a reedição da sexagenária, porém, mais atual do que nunca, teoria do capital humano, que propõe que os investimentos em educação ocupem papel central no progresso das sociedades. Não é novidade que os indivíduos mais escolarizados têm melhor inserção no mercado de trabalho e que tendem a lograr maiores rendimentos financeiros.

A formação superior, atualmente, caracteriza-se por exigir maior empenho dos alunos em seu processo formativo. Também, segundo Mora Ruiz (1999), uma série de fatores socioculturais e econômicos, como o nível educativo e ocupacional dos pais e a existência de um maior ou menor acesso aos ambientes culturais (ou à cultura letrada), condiciona o êxito dos alunos na educação superior.

Na complexidade do problema a ser enfrentado na organização institucional e curricular para acolher maior número de estudantes e, ao mesmo tempo, promover a atualização programática requerida pelos novos tempos da ciência, da cultura e do desenvolvimento social e econômico do Brasil, destacamos, neste estudo, uma questão: como reconhecer a diferente (ou insuficiente) preparação acadêmica da nova geração universitária e trazer esta situação ao planejamento institucional e didático-pedagógico de modo a evitar o baixo desempenho dos estudantes, o abandono dos estudos e, consequentemente, desperdícios de recursos públicos e privados com a educação superior?

Neste sentido, o presente estudo - de caráter exploratório, que faz parte de uma pesquisa mais ampla no âmbito de uma tese de doutorado em ciências da educação que consistiu em conhecer os fatores que estão associados ao desempenho acadêmico dos estudantes nos dois primeiros semestres de estudos na universidade - teve por objetivo conhecer alguns aspectos referentes às características dos estudantes que transitam na educação superior, bem como suas percepções sobre a experiência educativa prévia ao acesso à universidade e, assim, produzir conhecimento que permitisse melhor predição, explicação e entendimento dos fatores condicionantes do desempenho acadêmico dos alunos na educação superior no Brasil.

No contexto latino-americano, evidenciam-se iniciativas de realizar estudos sobre a transição ensino médio-educação superior, mas existe a tendência de deixar às instâncias encarregadas pelas estatísticas oficiais a realização desses estudos. Isso faz com que não exista uma articulação entre as investigações nem unanimidade entre os critérios de análise. Essa realidade implica a instauração de novas ações em relação ao acesso ao ensino superior, como a elaboração de planos de orientação acadêmica visando a intervenções para a melhora da qualidade da educação superior.

\section{O acesso à educação superior}

O substancial aumento de alunos na educação superior, evidenciado na última década do século 20, especialmente na rede privada, ocorreu sem planificação prévia ou processos efetivos de regulação e avaliação, 
questão que colocou em tela de juízo a qualidade da educação. Em paralelo, ocorreu também forte expansão do acesso à educação básica. São mudanças importantes do ponto de vista social e promissoras para o desenvolvimento do País, mas que implicam recepcionar, nas universidades, jovens com perfil sociocultural e educacional distinto, assim como oferecer-lhes conteúdos e condições de aprendizagem significativamente diferentes.

Ao analisarmos o acesso à educação superior a partir da perspectiva do aluno, faz-se pertinente retomarmos o conceito de transição acadêmica, definido pelo grupo de pesquisa TRALS (Transições Acadêmicas e Laborais) ${ }^{1}$ (2002, p. 4) como:

[...] o processo iniciado pelos estudantes com a escolha de uma trajetória acadêmica e um futuro campo profissional durante os estudos de Ensino Médio e que culmina com a superação dos créditos matriculados correspondentes a dois semestres de estudos na Universidade.

Este processo, explicam Figuera e Torrado (2002, p. 2), "implica tanto a pessoa que transita como o seu contexto". De acordo com Cabrera (2005), a transição ensino médio-educação superior comporta um salto qualitativo da educação obrigatória à autônoma, com todas as descontinuidades sociopedagógicas implicadas.

No Brasil, de acordo com a Lei de Diretrizes e Bases (Brasil, 1996), os cursos de ensino médio têm como finalidade consolidar e aprofundar, em um período mínimo de três anos, os conhecimentos adquiridos na educação fundamental obrigatória e habilitar o estudante a prosseguir os estudos ou prepará-lo para o exercício profissional de nível técnico.

Podemos mencionar que existe um transcurso contínuo e gradual para o estudante integrar-se ao novo entorno acadêmico. Esse processo tem um caráter de transformação multifatorial devido à intervenção de diferentes fatores sociais, culturais, individuais e acadêmicos que afetam o nível do impacto da mudança no período específico em que ela ocorre, sendo esse impacto mediado pela natureza do apoio disponível e por estratégias de coping ${ }^{2}$ com relação às mudanças inerentes ao próprio indivíduo (Schlossberg, 1984).

As características individuais dos estudantes assumem um papel mediador dos efeitos produzidos pelo contexto acadêmico no acesso e na adaptação à educação superior (Pascarella; Terenzini, 1991). Por exemplo, a respeito da influência da universidade na aprendizagem e no desenvolvimento dos alunos, diversos autores estão de acordo que essa influência, ainda que positiva, não é determinante, sendo mediada por outras variáveis psicossociais dos estudantes, como seus projetos e interesses, suas estratégias ao enfrentar as situações, seu status social ou seu gênero (Astin, 1997; Chapman; Pascarella, 1983).

Corominas e Isus (1998) mencionam que diversas universidades do mundo desenvolvem constantemente programas de orientação acadêmica que incluem intervenções para facilitar o processo de inserção na educação superior. No entanto, no Brasil, ainda são incipientes as práticas neste sentido. 
A ausência de conhecimento rigoroso sobre os fatores que incidem na transição do ensino médio à educação superior, contrastada com a complexidade do sistema educativo e social atual, dificulta a ação orientadora e educativa, bem como a elaboração de propostas coerentes e efetivas para o êxito dessa transição.

\section{O desempenho acadêmico como indicador de qualidade do acesso à educação superior}

A problemática do baixo desempenho acadêmico do estudante é um tema de debate constante e atual devido às repercussões que acarreta a diversos âmbitos educacionais. Segundo Rodríguez, Fita e Torrado (2004), no âmbito nacional, supõe um incremento crescente no gasto público; já no âmbito universitário, para os mesmos autores, supõe uma redução do desempenho geral da instituição e uma sobrecarga das salas de aula, com estudantes que não concluirão o curso ou que empregarão mais tempo do que o estabelecido para obter a titulação.

No âmbito individual, o baixo desempenho acadêmico tem como consequência o abandono ou o atraso nos estudos, o que é uma fonte provável de insatisfação pessoal e gera deterioração da personalidade e frustração (Latiesa, 1986; Pozo; Hernández, 1997). Esses pressupostos teóricos revelam a pertinência em se conceituar o desempenho acadêmico antes de examinar suas diferentes perspectivas de análise. Segundo Touron (1984), em termos educativos, o desempenho é um dos resultados da aprendizagem, suscitado pela atividade educativa do professor e produzido no aluno, ainda que esteja claro que nem toda aprendizagem é produto da ação docente.

Para Jiménez (1994), o desempenho acadêmico é concebido como um construto que não só contempla atitudes e motivação dos alunos, mas também outras variáveis intervenientes, como aspectos docentes, relação professor-aluno, entorno familiar etc. Essas definições amplas nos remetem à necessidade de buscar definições operacionais que possibilitem a compreensão e a análise do desempenho acadêmico, como o fazem diversos autores. Gimeno Sacristán (1976), em seu estudo sobre a relação entre desempenho escolar e personalidade, estima que as notas, com certas reservas, são um instrumento valioso de comparação entre ambos os aspectos. Latiesa (1992), por sua vez, diferencia o desempenho em sentido amplo (êxito, atraso e abandono) e em sentido restrito (notas).

Não obstante, vários autores concordam que o desempenho em sentido restrito é o indicador mais viável para definir o desempenho acadêmico. Rodríguez, Fita e Torrado (2004) estão de acordo com essa afirmação, principalmente se as notas refletem os logros nos diferentes componentes (ou dimensões) do produto universitário (aspectos acadêmicos, profissionais e pessoais), ou seja, o perfil completo da formação. A partir desses supostos, considera-se pertinente adotar o conceito de desempenho acadêmico como 
a relação entre o potencial (input) do estudante e o produto que se logra (aprendizagem).

Constata-se ainda que o desempenho acadêmico constitui-se em um potente indicador de qualidade de uma instituição. Conforme afirma a Commission on Higher Education (MSACS, 1995, p. 32): "O desempenho acadêmico dos estudantes é um indicador chave para determinar se uma instituição está alcançando os seus objetivos". Para Rodríguez (2003, p. 94), "a perspectiva da qualidade como eficiência econômica fez com que a atenção aos logros se constitua em um referencial fundamental na moderna avaliação da qualidade das universidades". Cabe acrescentar que os indicadores da transição para a educação superior são igualmente considerados como potentes demonstradores da qualidade de um sistema educacional.

Para fins deste estudo, analisamos algumas investigações que contemplaram os resultados do produto ao final do processo de transição para a educação superior. Verificamos que as pesquisas mais importantes sobre o desempenho acadêmico foram realizadas a partir da década de 1990, com maior incidência a partir dos anos 2000. Tais estudos podem ser classificados pela análise da transição com base na natureza dos fatores de êxito. Esse critério foi o mais utilizado, uma vez que atende aos tipos de variáveis mais comumente associadas ao sucesso ou ao fracasso acadêmico. Sendo assim, foi possível classificar os estudos segundo os modelos psicológico, sociológico, psicossocial e o modelo eclético de interação.

O modelo psicológico centra-se fundamentalmente no estudo dos fatores de aptidão e de personalidade. Esse modelo foi a linha pioneira da transição para a educação superior e do desempenho acadêmico. Existem inúmeras pesquisas que abordam as características dos alunos e professores em diversos contextos, por exemplo: Boulter (2002); Bauer e Liang (2003); Tuckman (2003), entre outros.

O modelo sociológico apresenta a dificuldade de isolar as variáveis determinantes devido à própria dimensão do contexto sociológico ou à dificuldade de aferir e analisar os fatores. A importância das variáveis ambientais sempre foi reconhecida ainda que não analisada, pois fazem referência aos modelos estruturais e estáticos do contexto familiar, institucional e social e a seus aspectos dinâmicos. A aproximação sociológica mais tradicional baseia-se nos fatores da estrutura social, em especial a origem social. No entanto, as correntes ambientalistas ocupam um lugar importante na pesquisa sobre o assunto.

A maioria das pesquisas inclui as variáveis pessoais, familiares e escolares para explicar o desempenho acadêmico especificamente na educação superior. Essa postura assume que os estudantes trazem consigo uma variedade de atributos (sexo e capacidade), origem familiar (status social, expectativas familiares) e experiências pré-universitárias (sucesso no ensino médio e/ou outros estudos prévios). Todos esses fatores, juntos ou separados, influem no desempenho acadêmico do estudante. Não existem estudos centrados somente na perspectiva de análise sociológica para explicar o êxito da transição para a educação superior. 
O modelo psicossocial, por sua vez, baseia-se na crescente importância do valor dos processos interpessoais mais próximos e imediatos ao próprio indivíduo. De acordo com Clemente, Albiñana e Doménech (1997), foram adotadas duas posturas generalizadas em face desse modelo. Uma postura tentou examinar os processos a partir de um ponto de vista externo, observando como determinadas variáveis de estrutura (âmbito familiar ou escolar) ou de processo (atitudes dos demais para com o sujeito) atuavam sobre o indivíduo. A outra tentou analisar essa mesma influência, porém, partindo de um marco de referência interno por meio do significado e da repercussão dos aspectos do sujeito como ele os percebe. É possível encontrar estudos que adotam ambas as posturas, como os de Astin (1970), Benjamín e Hollings (1997), Pritchard e Wilson (2003) e outros.

Portanto, a partir de um exame sobre os modelos mencionados, pode-se evidenciar que as variáveis de personalidade e as aptidões (competências e habilidades) são as que se sobressaem mais frequentemente como fatores explicativos do sucesso da transição para a educação superior. Todavia, com uma análise valorativa a posteriori dos modelos anteriores, concretiza-se o modelo eclético de interação. Esse modelo reconhece a influência das dimensões estáticas e dinâmicas da personalidade (inteligência, caráter, atitudes, motivações), confirma o valor determinativo de certas variáveis sociais, tanto de estrutura como de processo, e aceita, principalmente, o valor do "eu" como elemento integrador e determinante da conduta. Neste âmbito, os estudos mais conhecidos são os de Elkins, Braxton e James (2000), Trals (2002) e Strauss e Wolkwein (2004).

O modelo eclético de interação, portanto, permite concluir que a transição à educação superior, desde a perspectiva do desempenho acadêmico, da satisfação dos estudantes com relação às suas conquistas, aos processos de progresso e à adaptação ao meio, constitui-se em um enfoque teórico que permite explicar mais adequadamente essa transição.

\section{Metodologia da pesquisa}

Os resultados aqui apresentados são referentes à primeira etapa de um estudo mais amplo no âmbito de uma tese de doutorado em ciências da educação. As questões de investigação foram as seguintes:

1. Qual o perfil de entrada dos alunos que ingressaram em diferentes cursos de licenciatura (História, Letras, Matemática e Biologia) da Universidade Federal do Rio Grande do Sul?

2. Qual a percepção dos alunos sobre a experiência educativa prévia (Background escolar) ao acesso à educação superior?

Cabe salientar que, em termos metodológicos, a presente investigação é do tipo exploratório-descritiva de abordagem quantitativa, uma vez que a intenção foi produzir conhecimento que permitisse uma melhor predição, explicação e entendimento dos fatores associados ao desempenho 
acadêmico dos alunos na educação superior no Brasil. Para a realização do estudo, utilizou-se um questionário construído pelo grupo de pesquisa TRALS, que foi sujeito a um processo de validação em contexto brasileiro e, posteriormente, foi utilizado nesse estudo.

O questionário aplicado tratou de coletar os dados referentes ao acesso à universidade e estabelece dimensões em relação às características sociodemográficas, socioculturais e econômicas, à qualidade na escolha do curso e à experiência educativa prévia ao referido acesso. Hernández, Fernández e Baptista (1991, p. 66) definem o questionário como "um conjunto de perguntas sobre uma ou mais variáveis a serem medidas (categorias a descrever)". Trata-se de um instrumento que tem a capacidade de coletar informações variadas em uma única aplicação. Desse modo, o questionário é um recurso útil por sua aceitação conjunta de seções estruturadas, semiestruturadas e abertas (Cabrera; Espin, 1986).

De acordo com o delineamento metodológico desta investigação, procedeu-se ao tratamento estatístico dos inquéritos por questionário recorrendo-se ao programa SPSS (Statistical Package for Social Sciences), em sua versão 12.0. Quanto à análise dos dados, utilizou-se a técnica estatística descritiva e inferencial. Os participantes (cf. Tabela 1) foram 227 alunos, do total da amostra composta por 312 sujeitos, que ocuparam as vagas disponíveis no primeiro semestre letivo, aprovados no vestibular e matriculados nos cursos de Matemática, Biologia, Letras e História da UFRGS. Para realizar a análise desta pesquisa, agruparam-se os quatro cursos em duas áreas de conhecimento: Humanidades (representada pelos cursos de História e Letras) e Ciências (representada pelos cursos de Biologia e Matemática). ${ }^{3}$ Considerando-se a amostra total e o total de entrevistados, a margem de erro para os resultados do estudo atinge 3,5\% sobre a amostra entrevistada.

Tabela 1 - Alunos que Participaram do Estudo

\begin{tabular}{|l|c|c|c|c|}
\hline \multicolumn{1}{|c|}{ Curso } & População & Amostra & $\begin{array}{c}\text { \% de } \\
\text { respostas }\end{array}$ & $\begin{array}{c}\% \text { de } \\
\text { erro }\end{array}$ \\
\hline Biologia & 50 & 41 & 82 & 7 \\
\hline Matemática & 45 & 33 & 73 & 9 \\
\hline Total Ciências & 95 & 74 & 78 & 5,5 \\
\hline Letras & 132 & 86 & 65 & 6 \\
\hline História & 85 & 67 & 79 & 6 \\
\hline Total Humanidades & 217 & 153 & 70 & 4 \\
\hline $\begin{array}{l}\text { Total Ciências }+ \\
\text { Humanidades }\end{array}$ & 312 & 227 & 73 & 3,5 \\
\hline
\end{tabular}

Fonte: Elaboração própria.

${ }^{3}$ Cabe explicitar que o desigual número de vagas oferecidas nos diferentes cursos conduziu à agrupação destas em duas áreas do conhecimento com o propósito de lograr uma amostragem mais representativa para a análise dos dados.

\section{Resultados e discussão}

Como produto desta pesquisa, são apresentados e discutidos os resultados referentes ao perfil de acesso dos estudantes e a percepção dos 
alunos sobre a experiência educativa prévia ao acesso à educação superior. Os dados são apresentados, primeiramente, com base numa análise global das áreas do conhecimento e, comparativamente, quando houver diferenças significativas entre as áreas de Ciências e Humanidades.

\section{O perfil de acesso dos estudantes}

- Características sociodemográficas

As características como sexo, idade e tipologia da instituição de origem nos brindam com informações básicas sobre os alunos. Estas informações podem explicar as diferenças na transição do ensino médio para a educação superior.

Em relação ao sexo dos alunos, que ingressam na UFRGS, ambas as áreas do conhecimento estão igualmente representadas por estudantes do sexo masculino e feminino. A principal diferença sociodemográfica dos alunos que acedem aos cursos de licenciatura da UFRGS está relacionada à idade. 55\% dos estudantes têm mais de 20 anos, e não se observam diferenças estatísticas por área do conhecimento. Este dado é coerente com a problemática da distorção idade/série, tema constantemente discutido e analisado no Brasil devido ao ingresso tardio no sistema escolar, a repetição de séries e o abandono dos estudos por temporadas. Esta situação, analisada por Avanzini (1969), pode ser um fenômeno condicionante do baixo desempenho acadêmico.

Quanto à tipologia das instituições de ensino de procedência dos alunos, observou-se que $51 \%$ dos alunos, de ambas as áreas do conhecimento, são oriundos de instituições privadas. Não foram observadas diferenças significativas por área do conhecimento.

- Background sociocultural e econômico

Os antecedentes familiares e econômicos podem explicar a transição dos alunos para a universidade. Por esta razão, é necessário considerar alguns pontos relacionados, tais como os estudos do pai e da mãe, o apoio familiar, a manutenção e o financiamento dos estudos. Estes aspectos em conjunto explicam as influências do ambiente sociocultural e econômico. Pitchard e Wilson (2003) constataram que existe uma série de variáveis preditoras do desempenho acadêmico; entre elas, os antecedentes educativos dos pais e familiares.

No contexto educativo desta investigação, a maioria dos alunos entrevistados (72\%) forma parte da segunda geração na educação superior, ou seja, o pai, a mãe ou algum irmão ingressou anteriormente na educação superior. Os resultados demonstram que o nível de escolaridade dos pais dos alunos em Ciências (58\%) é superior ao nível de escolaridade dos pais dos alunos das Humanidades (47\%). A respeito do apoio dos pais com relação aos estudos empreendidos, a análise de médias para amostras independentes manifesta que os pais dos alunos de Ciências têm maior interesse cultural 
e se preocupam mais com os estudos dos filhos do que os pais dos alunos de Humanidades.

A partir da literatura revisada evidenciou-se que a variável suporte econômico está associada a uma transição de êxito à universidade, pois permite dedicação exclusiva aos estudos. A maioria dos estudantes entrevistados não exerce qualquer atividade de trabalho (78\%), sendo a família responsável por manutenção e financiamento dos estudos. Por área de agrupação, 84\% dos alunos de Ciências dependem economicamente da família, enquanto $62 \%$ dos alunos de Humanidades se encontram nessa situação. Com base nos resultados apresentados, evidencia-se que os alunos de Ciências provêm de um ambiente sociocultural e econômico mais favorável em relação ao ambiente dos alunos de Humanidades.

- Qualidade da escolha do curso

De acordo com Rodríguez (2003), a dimensão "qualidade da escolha do curso" pode ser analisada a partir da trajetória educativa dos estudantes ou de informações e objetivos sobre o curso escolhido e afirma, ainda, que a escolha adequada de estudos é um indicador de permanência na universidade. Assim, foram considerados aspectos relacionados aos estudos anteriores, aos objetivos com o curso escolhido e às influências nessa escolha.

A maioria dos alunos (66\%) afirma ter ingressado pela primeira vez na educação superior.

Sobre os objetivos dos alunos com o curso escolhido, em uma escala de 1 a 5 (pouco e muito), a variável aquisição de conhecimento para exercer a profissão escolhida foi avaliada como fundamental (4.84) e não se observaram diferenças significativas entre as áreas do conhecimento. Com relação às influências na escolha do curso, o fator conexão com os estudos e características pessoais foi o mais estimado pelos alunos no momento da escolha do curso (4.41), sem diferenças significativas entre os grupos. A respeito da satisfação com o curso escolhido, 90,5\% dos alunos mostram-se satisfeitos com a escolha.

\section{Percepção sobre a experiência educativa prévia (background escolar)}

Os alunos foram questionados sobre suas percepções acerca da experiência educativa prévia ao acesso à educação superior. Assim, verificamos qual o background que facilitou o acesso à UFRGS. Ao abordar essa dimensão, é necessário refletir sobre esse aspecto com base nas teorias sobre o desempenho acadêmico. Nesse sentido, mencionamos que a preparação para o ingresso na universidade é uma forma de evitar o abandono e o baixo desempenho acadêmico, portanto, é possível garantir a integração dos estudantes no ensino superior. 
Segundo asseveram Rodriguez e Gallego (1992), o desempenho acadêmico é uma conduta humana complexa que está em função de um sistema de variáveis endógenas e exógenas; é o resultado da avaliação do processo de ensino-aprendizagem que, normalmente, é mais normativa que criteriosa, está sempre em referência a um grupo e tem uma característica mais quantitativa do que qualitativa. A satisfação dos estudantes com a formação prévia recebida também é um fator importante a ser considerado, uma vez que essa é uma questão fundamental na aquisição de aprendizagens posteriores. Isso significa que uma boa base de conhecimento, hábitos de estudo e habilidades sociais desenvolvidos no nível secundário podem garantir o sucesso na formação do conhecimento quando ingressam na universidade.

- Preparação para o acesso à educação superior

Woosley (2003) constata que a adequada preparação para aceder à educação superior tem correlação positiva com o desempenho acadêmico. Nesse estudo, a maioria dos alunos pesquisados (69\%) considerou importante realizar aulas de reforço, além da escola, para ingressar na universidade. Averiguou-se que $81 \%$ dos alunos de Ciências tiveram aulas de reforço dos conteúdos aprendidos na escola para aprovação no exame de acesso à universidade, enquanto $63 \%$ dos estudantes de Humanidades tiveram aulas de reforço.

- Satisfação com a formação recebida no ensino médio

A formação recebida no ensino médio se constitui em uma base, tanto teórica como procedimental e atitudinal, que permite aos alunos lidar com a sua integração na educação superior. Portanto, a avaliação realizada pelos estudantes sobre sua formação anterior ao acesso à universidade é um elemento de análise fundamental. Neste estudo, 52\% dos alunos consideram-se satisfeitos com a formação recebida na escola. Dos alunos provenientes da escola pública, apenas 31\% estão satisfeitos com a sua formação, ao passo que $73 \%$ dos estudantes da rede privada estão satisfeitos com a formação educacional recebida.

-Valoração da experiência educativa na instituição de ensino médio

A transição para a educação superior é uma das transições mais importantes da trajetória escolar dos alunos que atingiram esse nível de formação (Corominas; Isus, 1998), de modo que a valoração da experiência no ensino médio é fundamental. As competências são definidas como um conjunto de habilidades e atitudes que facilitam o desenvolvimento e a aquisição de novas aprendizagens (Tejada, 1999).

Em efeito, o domínio de certas habilidades permite prever os fatores relacionados ao desempenho escolar. Nesse estudo, a avaliação dos aspectos 
importantes da experiência educacional na instituição de origem, em uma escala Likert de 1 a 5 ( 1 corresponde a "insatisfatório" e 5 a "excelente"), apresentou como resultado mais alto (3.88) a relação professor-aluno, item que também apresentou o menor grau de dispersão (0.937); em segundo lugar, os alunos avaliaram o desenvolvimento de atitudes e valores como "satisfatório" (3.51), com um desvio padrão de 1.122. Nas variáveis satisfação com a escola, capacitação nas diferentes matérias, habilidades de análise crítica, capacitação de diferentes técnicas de estudo e realização de trabalhos escolares, o ambiente de trabalho e a motivação em sala de aula foram estimadas como "regular" (3), e, finalmente, o item aprendizagem de idiomas foi classificado como "ruim" (2.45), apresentando um desvio padrão relativamente elevado (1.181).

A comparação de médias para amostras independentes entre as duas áreas demonstra que os estudantes de Ciências avaliam de forma mais positiva a experiência na instituição de origem. A autopercepção da capacidade intelectual e das competências predizem o ajuste acadêmico (Boulter, 2002).

- Motivação para afrontar os estudos

Weiner (1986) formula uma teoria da motivação em que as atribuições que o sujeito dá a si mesmo sobre seus sucessos e fracassos desempenham um papel central. Nessa perspectiva, o que realmente determina a motivação são as diferentes interpretações e avaliações que um indivíduo faz de seus próprios resultados acadêmicos (Valle et al., 1999). Uma grande porcentagem dos alunos (72\%) manifesta-se muito motivada para começar os estudos universitários. Não foram observadas diferenças nas duas áreas do conhecimento.

- Nota de acesso à universidade

Analisou-se, conforme Tabela 2, a nota de acesso dos estudantes de acordo com a área do conhecimento e a tipologia da instituição de origem. Ao realizar a comparação entre as médias de acesso, de acordo com o tipo de instituição de que os alunos se originaram, observou-se que existem diferenças significativas. Alunos oriundos das instituições privadas têm uma nota de acesso superior aos alunos provenientes das instituições públicas.

A transição para a educação superior assume um importante significado no que diz respeito à qualidade do sistema educativo. Consideram-se os indicadores da transição para a universidade como potentes indicadores da qualidade dos sistemas do ensino médio e da educação superior. Podemos relacionar as competências aprendidas na escola como elementos básicos do progresso que pode ser alcançado durante os estudos na universidade. 
Tabela 2 - Média da Nota de Acesso à Universidade por Tipo de Instituição de Origem e Area do Conhecimento

\begin{tabular}{l|l|l}
\multicolumn{1}{c|}{ Pública e Humanidades } & \multicolumn{1}{c|}{ Privada e Humanidades } & \multicolumn{1}{c}{ Subtotal } \\
\hline $\mathrm{X}=557,99$ & $\mathrm{X}=572,77$ & $\mathrm{X}=565,2746$ \\
\hline $\mathrm{S}=46,64$ & $\mathrm{~S}=53,80$ & $\mathrm{~S}=50,64456$ \\
\hline $\mathrm{N}=73$ & $\mathrm{~N}=71$ & $\mathrm{~N}=144$ \\
\hline Pública e Ciências & Privada e Ciências & Subtotal \\
\hline $\mathrm{X}=556,98$ & $\mathrm{X}=600,65$ & $\mathrm{X}=580,7428$ \\
\hline $\mathrm{S}=59,24$ & $\mathrm{~S}=49,44$ & $\mathrm{~S}=58,00993$ \\
\hline $\mathrm{N}=31$ & $\mathrm{~N}=37$ & $\mathrm{~N}=68$ \\
\hline Subtotal & Subtotal & Total \\
\hline $\mathrm{X}=557,6872$ & $\mathrm{X}=582,3002$ & $\mathrm{X}=570,2361$ \\
\hline $\mathrm{S}=50,43103$ & $\mathrm{~S}=5378510$ & $\mathrm{~S}=53,48696$ \\
\hline $\mathrm{N}=104$ & $\mathrm{~N}=108$ & $\mathrm{~N}=212$ \\
\hline
\end{tabular}

Fonte: Elaboração própria.

Legenda: $\mathrm{X}=$ Média; $\mathrm{S}=$ Desvio Padrão; $\mathrm{N}=$ Amostra

\section{Considerações finais}

O acesso ao ensino superior é um processo complexo no qual interagem múltiplos fatores e agentes educativos, como educadores de escolas de ensino médio, departamentos de orientação educacional, professores e também as instituições de ensino superior. Portanto, retornamos ao questionamento que conduziu a presente análise sobre o acesso à educação superior: como reconhecer a diferente (ou insuficiente) preparação acadêmica da nova geração universitária e trazer essa situação ao planejamento institucional e didático-pedagógico de modo a evitar o baixo desempenho dos estudantes, o abandono dos estudos e, consequentemente, desperdícios de recursos públicos e privados com a educação superior, entre outros tantos problemas?

Forner e outros autores nos fornecem (2000, p. 3) uma possível resposta quando afirmam que:

[...] as investigações se ocuparam em buscar as explicações do sucesso ou fracasso da transição a Educação Superior nos próprios estudantes, sem considerar a influência dos sistemas de procedência (Ensino Médio) e de destino (Educação Superior), como se a responsabilidade da transição fosse do sujeito que transita e não dos sistemas pelos quais transita. (Forner et al. , 2000, p. 3)

De acordo com Alvarez e Fita (2005, p. 2), "um plano de intervenção é visto como uma prioridade em todo o processo de transição. A orientação deve tornar-se uma mais-valia para o desenvolvimento global dos alunos e melhorar a própria escola". Pode-se abordar uma intervenção por meio da adoção de diferentes modelos de orientação. Os autores propõem uma 
intervenção cuja contextualização englobe a realidade atual do ensino superior, que inclua o indivíduo e a instituição e que trate, entre outros fatores, da diversidade dos alunos em relação à idade, origem de diferentes contextos educativos, tendo em conta os novos papéis e funções a serem desempenhados pela educação superior. Nesse sentido, evidencia-se que a orientação é de fundamental importância quando se trata da qualidade da educação. Alvarez e Fita (2005) analisam que a educação superior terá qualidade na medida em que for capaz de:

1. Incentivar a comunicação entre os diferentes agentes educativos.

2. Fomentar a formação e a motivação.

3. Afrontar o fracasso escolar de forma abrangente.

4. Dispor do uso de novas tecnologias e promover a capacidade de inovar.

5. Afrontar a avaliação para a melhoria do processo educativo.

6. Prestar apoio através de uma intervenção orientadora.

Os autores argumentam que se nos centrarmos no estudo das transições acadêmicas, estas serão confrontadas não somente por uma perspectiva estritamente acadêmica (desempenho), mas também incorporarão variáveis pessoais, familiares, sociais, acadêmicas e profissionais que afetarão o processo de transição para a educação superior (Corominas; Isus, 1998; Figueira; Torrado, 2000).

A assistência à transição envolve o monitoramento contínuo e a ação preventiva para mediar o processo e envolver os educadores. Quanto às dimensões ou áreas de intervenção, Alvarez e Fita (2005) demonstram que uma intervenção de aconselhamento no processo de transição ensino médio-educação superior deve incluir as seguintes dimensões: conhecimento prévio, conhecimento do contexto socioeducativo, adaptação ao novo contexto, concepções prévias sobre o ensino superior, informação acadêmica e profissional, motivação, habilidades acadêmicas, competências para a aprendizagem de novas competências, apoio familiar, desempenho escolar etc. Em suma, deve-se proporcionar um ambiente de colaboração entre todos os agentes implicados no processo para assegurar uma orientação qualificada aos estudantes que acedem ao ensino superior.

O desafio está posto aos professores universitários e ao conjunto dos profissionais que atuam nas instituições e na gestão das políticas públicas de educação superior.

\section{Referências bibliográficas}

ÁLVAREZ, M. La orientación profesional en la universidad. Barcelona: Cedecs, 1995.

ALVAREZ, M.; FITA, E. La intervención orientadora en la transición Bachillerato-Universidad. Bordón, Rioja, v. 57, n. 1, p. 5-27, 2005. 
ASTIN, A. How good is your institution retention rate. Research in Higher Education, [New York], v. 38, p. 647-657, 1997.

ASTIN, A. The methodology of research on college impact. Sociology of Education, Califórnia, v. 43, p. 223-254, 1970.

AVANZINI, G. El fracasso escolar. [Barcelona]: Herder, 1969. 187 p.

BAUER, K.; LIANG, K. The effect of personality and precollege: characteristics on first-year activities and academic performance. Journal of College Students Development, Maryland, v. 2, n. 44, p. 277-290, 2003.

BENJAMIN, M.; HOLLINGS A. Student satisfaction: test of an ecological model. Journal of College Student Development, Maryland, v. 3, n. 38, p. 213-228, 1997.

BOUTLER, L. Self-concept as a predictor of college freshman academic adjustment. College Student Journal, Chicago, v. 2, n. 36, p. 234-246, 2002.

BRASIL. Lei no 9.394, de 20 de dezembro de 1996. Estabelece as diretrizes e bases da educação nacional. Diário Oficial da União, Brasília, DF, 23 nov. 1996. Disponível em: < http://www.planalto.gov.br/ ccivil_03/leis/19394.htm>.

CABRERA, F.; ESPIN, J. Medición y evaluación educativa. Barcelona: PPU, 1986.

CABRERA, G. La transición preclínico-clínico en la carrera de medicina: una aproximación a su estudio como transición intracurricular. 2005. Tese (Doutorado em Educação) - Universidade de Barcelona, Barcelona, 2005.

CHAPMAN, D. W.; PASCARELLA, E. T. Predictors of academic and social integration of college students. Research in Higher Education, [New York], n. 19, p. 295-321, 1983.

CLEMENTE, A.; ALBIÑANA, P.; DOMÉNECH, F. Predicción del rendimiento académico en estudiantes de secundaria a través de los factores de inteligencia, socialización, desadaptación escolar, autoconcepto y personalidad. Revista de Psicología de la Educación, Valência, n. 22, p. 55-68,1997.

COROMINAS, E.; ISUS, S. Transiciones y orientación. Revista de Investigación Educativa, Barcelona, v. 16, n. 2, p. 155-184, 1998. 
DELORS, J. (Coord.). Educação: um tesouro a descobrir. Relatório para a UNESCO da Comissäo Internacional sobre Educaçäo para o século XXI. Porto: Edições Asa, 1999.

ELKINS, S. A.; BRAXTON, J. M.; JAMES, G. W. Tinto's separation stage and its influence on first-semester college student persistence. Research in Higher Education, [New York], v. 2, n. 42, p. 251-268, 2000.

FIGUERA, P.; TORRADO, M. El proceso de transición de bachillerato a la universidad: factores de éxito. Quaderns Institucionals, Barcelona, n. 2, p. 41-55, 2000.

FORNER, A. et al. La transición secundaria-universidad: los alumnos de LOGSE: comunicación en el 1r Congreso Internacional Docencia Universitaria e Innovación. Barcelona: ICE's/UB/UAB/UPC, 1998. 1 CDROM.

GIMENO SACRISTÁN, J. Autoconcepto, sociabilidad y rendimiento escolar. Madrid: MEC, 1976.

HERNÁNDEZ R.; FERNÁNDEZ C.; BAPTISTA P. Metodología de la Investigación. México: Mc Graw-Hill Interamericana, 1991.

JIMÉNEZ, M. Competencia social: intervención preventiva en la escuela. Universidad de Alicante. Infancia y Sociedad: Revista de Estudios, La Rioja, n. 24, p. 21-48, 1994.

LATIESA, M. Estudio longitudinal de una cohorte de alumnos de la Universidad Autónoma de Madrid: análisis de la deserción universitaria. In: LATIESA, M. (Comp.). Demanda de educación superior y rendimiento académico en la universidad. Madrid: CIDE-SGCU, 1986. p. 399-441.

LATIESA, M. La deserción universitaria. Madrid: C.I.S., 1992.

MIDDLE STATES ASSOCIATION OF COLLEGES AND SCHOOLS (MSACS). Commission on Higher Education. Framework for outcomes assessment. Philadelphia: Commission on Higher Education, 1995.

MORA RUIZ, J. G. Calidad y rendimiento en las instituciones universitarias. Madrid: Consejo de Universidades, Secretaría General, 1999.

PASCARELLA, E. T.; TERENZINI, P. T. How college affects students. San Francisco: Josey Bass, 1991.

PERRENOUD, P. Construir as competências desde a escola. Porto Alegre: Artmed, 1999. 
POZO, C.; HERNÁNDEZ, J. M. El fracaso académico en la universidad: propuesta de un modelo de explicación e intervención preventiva. In: APODACA; LOBATO (Ed.). Calidad en la universidad: orientación y evaluación. Barcelona: Laertes, 1997. p. 137-152.

PRITCHARD, M.; WILSON, G. Using emotional and social factors to predict student success. Journal of College Student Development, Maryland, v. 44, p.18-27, 2003.

RODRÍGUEZ, J. L.; GALLEGO, S. Lenguaje y rendimiento académico. Salamanca: Univ. de Salamanca, 1992.

RODRÍGUEZ, S. La problemática del rendimiento en la transición secundaria-universidad. In: JORNADAS SOBRE EL ACCESO A LA UNIVERSIDAD, 10., 2003. Actas... Sevilla: Universidad de Sevilla, 2003. p. 93-113.

RODRÍGUEZ, S.; FITA, E.; TORRADO, M. El rendimiento académico en la transición secundaria- universidad. Revista de Educación, Madrid, n. 334, p. 391-414, 2004.

SCHLOSSBERG, N. Counseling adults in transition. New York: Springer Publishing Company, 1984.

STRAUSS, L.; VOLKWEIN, F. Predictors of student commitment at two and four year institutions. Research paper presented at ASHE, Richmond, VA, 2004.

TEJADA, J. F. Acerca de las competencias profesionales. Revista Herramientas, Madrid, v. 56, p. 20-30, 1999.

TOURON, J. Factores del rendimiento académico en la Universidad. Pamplona: EUNSA, 1984.

TRALS (Grup de Recerca Sobre Transicions Acadèmiques I Laborals). El rendiment acadèmic i la trajectória acadèmica en els dos primers anys de la universidad. Barcelona: Universidad de Barcelona, 2002.

TUCKMAN, B. The effect of learning and motivation strategies training on college students' achievement. Journal of College Student Development, Maryland, v. 3, n. 44, p. 430-437, 2003.

VALLE, A. et al. Atribuciones causales, autoconcepto y motivación en estudiantes con alto y bajo rendimiento académico. Revista Española de Pedagogía, Madrid, v. 214, p. 525-546, 1999. 
WEINER, B. An attributional theory of achievement motivation ad emotion. Psychological Review, Washington, DC, v. 92, n. 4, p. 548-573, 1986.

WOOSLEY, S. Stop-out or drop-out? an examination of college withdrawals and re-enrollments. Journal of College Student Retention: research, theory and practice, Bedford, NH, v. 5, n. 3, p. 293-303, 2003.

Caterine Vila Fagundes, doutora em educação pela Universidade de Barcelona, é pesquisadora associada da Universidade Federal do Rio Grande do Sul (UFRGS), Porto Alegre, Brasil, no Núcleo de Politicas e Gestão da Educação, pesquisadora e consultora do Observatório de Las Relaciones Europa y América Latina (OBREAL) - Universidade de Barcelona, Espanha. caterine.fagundes@gmail.com

Recebido em 4 de setembro de 2013.

Revisado em 27 de junho de 2014.

Aprovado em 14 de julho de 2014. 